\title{
Dual role of HupF in the biosynthesis of [NiFe] hydrogenase in Rhizobium leguminosarum
}

\author{
Marta Albareda ${ }^{1,2}$, Hamid Manyani ${ }^{1,2,5}$, Juan Imperial ${ }^{1,2,3}$, Belén Brito ${ }^{1,2}$, Tomás Ruiz-Argüeso ${ }^{1,2}$, August Böck ${ }^{4}$ \\ and Jose-Manuel Palacios ${ }^{1,2^{*}}$
}

\begin{abstract}
Background: [NiFe] hydrogenases are enzymes that catalyze the oxidation of hydrogen into protons and electrons, to use $\mathrm{H}_{2}$ as energy source, or the production of hydrogen through proton reduction, as an escape valve for the excess of reduction equivalents in anaerobic metabolism. Biosynthesis of [NiFe] hydrogenases is a complex process that occurs in the cytoplasm, where a number of auxiliary proteins are required to synthesize and insert the metal cofactors into the enzyme structural units. The endosymbiotic bacterium Rhizobium leguminosarum requires the products of eighteen genes (hupSLCDEFGHIJKhypABFCDEX) to synthesize an active hydrogenase. hupF and hupK genes are found only in hydrogenase clusters from bacteria expressing hydrogenase in the presence of oxygen.
\end{abstract}

Results: HupF is a HypC paralogue with a similar predicted structure, except for the C-terminal domain present only in HupF. Deletion of hupF results in the inability to process the hydrogenase large subunit HupL, and also in reduced stability of this subunit when cells are exposed to high oxygen tensions. A $\Delta$ hupF mutant was fully complemented for hydrogenase activity by a C-terminal deletion derivative under symbiotic, ultra low-oxygen tensions, but only partial complementation was observed in free living cells under higher oxygen tensions (1\% or 3\%). Co-purification experiments using StrepTag-labelled HupF derivatives and mass spectrometry analysis indicate the existence of a major complex involving HupL and HupF, and a less abundant HupF-HupK complex.

Conclusions: The results indicate that HupF has a dual role during hydrogenase biosynthesis: it is required for hydrogenase large subunit processing and it also acts as a chaperone to stabilize HupL when hydrogenase is synthesized in the presence of oxygen.

Keywords: Metalloenzyme, [NiFe] cofactor, Nitrogen fixation, Hydrogenase

\section{Background}

[NiFe] hydrogenases are enzymes that catalyze the oxidation of hydrogen into protons and electrons, to use $\mathrm{H}_{2}$ as energy source, or the production of hydrogen through proton reduction, as an escape valve for the excess of reduction equivalents in anaerobic metabolism. These enzymes, described in a wide variety of microorganisms, contain two subunits of $c a$. 65 and $30 \mathrm{kDa}$, respectively. The hydrogenase large subunit contains the active center of the enzyme, a heterobimetallic $[\mathrm{NiFe}]$ cofactor unique

\footnotetext{
* Correspondence: jose.palacios@upm.es

${ }^{1}$ Centro de Biotecnología y Genómica de Plantas (C.B.G.P.), Universidad Politécnica de Madrid, Campus de Montegancedo, Carretera M40- km 37.7, 28223 Pozuelo de Alarcón, Madrid, Spain

${ }^{2}$ Departamento de Biotecnología, Escuela Técnica Superior de Ingenieros, Agrónomos, Universidad Politécnica de Madrid, Ciudad Universitaria s/n, 28040 Madrid, Spain

Full list of author information is available at the end of the article
}

in nature, in which the Fe atom is coordinated with two cyano and one carbonyl ligands; the hydrogenase small subunit contains three Fe-S clusters through which electrons are conducted either from $\mathrm{H}_{2}$ to their primary acceptor $\left(\mathrm{H}_{2}\right.$ uptake), or to protons from their primary donor $\left(\mathrm{H}_{2}\right.$ evolution) [1].

Biosynthesis of $[\mathrm{NiFe}]$ hydrogenases is a complex process that occurs in the cytoplasm, where a number of auxiliary proteins are required to synthesize and insert the metal cofactors into the enzyme structural units [2]. In most Proteobacteria, genetic determinants for hydrogenase synthesis are arranged in large clusters encoding ca. 15-18 proteins involved in the process. Most hydrogenase genes are conserved in different proteobacterial hydrogenase systems, suggesting an essentially conserved mechanism for the synthesis of these metalloenzymes [3]. The biosynthesis of the hydrogenase [NiFe] cofactor 
and its transfer into the hydrogenase large subunit have been thoroughly studied in the Escherichia coli hydrogenase-3 system [2]. In that system, cyano ligands are synthesized from carbamoylphosphate through the concerted action of HypF and HypE proteins [4,5] and transferred to an iron atom exposed on a complex formed by HypC and HypD proteins [6]. The source and biosynthesis of the $\mathrm{CO}$ ligand likely follows a different path [7-9] whose details are still unknown, although recent evidence suggests that gaseous $\mathrm{CO}$ and an intracellular metabolite might be sources for the ligand [10]. When the iron is fully coordinated, HypC transfers it to pre-HycE, the precursor of the large subunit of E. coli hydrogenase-3. After incorporation of the precursor cofactor into $\mathrm{HycE}$, proteins $\mathrm{HypA}, \mathrm{HypB}$, and SlyD mediate $\mathrm{Ni}$ incorporation into the active site [11]. After nickel insertion, the final step is the proteolytic processing of the hydrogenase large subunit by a nickeldependent specific protease [12].

Hydrogen is produced in soils as a result of different metabolic routes. A relevant source of this element is the process of biological nitrogen fixation, in which at least $1 \mathrm{~mol}$ of hydrogen is evolved per mol of nitrogen fixed as a result of the intrinsic mechanism of nitrogenase [13]. As a consequence, many diazotrophic bacteria, including some rhizobia, induce [NiFe] hydrogenases along with nitrogenase to recover part of the energy lost as hydrogen [14]. The genome of the legume endosymbiotic bacterium Rhizobium leguminosarum bv. viciae UPM791 encodes a single hydrogenase that is expressed under symbiotic conditions by the concerted action of eighteen genetic determinants (hupSLCDEFGHIJKhyp-ABFCDEX) clustered on the symbiotic plasmid [15]. Symbiotic expression of hydrogenase structural genes (hupSL) is controlled by the NifAdependent promoter $\mathrm{P}_{1}$ [16]. In addition, an FnrN-type promoter controls the expression of the hypBFCDEX operon under microaerobic and symbiotic conditions [17]. For practical purposes, the NifA-dependent hupSL promoter has been replaced by the FnrN-dependent fixN promoter $\left(\mathrm{P}_{f i x N}\right)$, thus allowing expression of hydrogenase in microaerobic vegetative cells [18]. A single FnrNdependent promoter drives the expression of hupSL and all downstream hydrogenase genes in cosmid pALPF1. This plasmid and its deletion derivatives, along with the hup-deleted R. leguminosarum strain UPM 1155, have been used as a model to study hydrogenase synthesis in this bacterium [19].

The $R$. leguminosarum hydrogenase cluster encodes two proteins (HupF and HupK) not present in E. coli but conserved in other hydrogenase systems such as those from Ralstonia eutropha [20], Bradyrhizobium japonicum [21], and Rhodobacter capsulatus [22]. In the case of Thiocapsa roseopersicina, HupK and two copies of HypC have been described [23].
HupF is a paralog of HypC but, apart from this, no further data are available on the function of this protein in the R. leguminosarum system. HoxL, the HupF homo$\log$ in the $R$. eutropha system, is essential for the synthesis of active hydrogenase [20]. Recently, a model has been proposed for the synthesis of the oxygen-tolerant hydrogenase from $R$. eutropha [24]. According to this model, the interaction between HoxV, the HupK homo$\log$ in that system, and HypC plays a key role as intermediate able to accommodate the $\mathrm{Fe}\left(\mathrm{CN}^{-}\right)_{2} \mathrm{CO}$ cofactor precursor from the HypCD complex prior to its incorporation into a complex containing the hydrogenase large subunit (HoxG) and HoxL [20]. This model is further supported by the fact that $\mathrm{HypC} 2$ from $T$. roseopersicina was able to interact with HupK and HypD [23].

In this work we present evidence indicating that R. leguminosarum chaperone HupF has a second role in hydrogenase biosynthesis: in addition to its proposed role in assisting the transfer of Fe-containing precursor cofactor from HupK to HupL, it plays a protective role on hydrogenase structural subunit HupL when cells are exposed to oxygen.

\section{Results}

The existence of hupF and hupK correlates with the presence of hypC in the genome of aerobic bacteria

A BLAST search for homologues to $R$. leguminosarum HupF and HupK proteins in a set of 408 completed genomes from Proteobacteria in the NCBI database revealed the presence of two hupF/hypC-like genes in 21 out of 77 proteobacterial genomes encoding [NiFe] hydrogenases. In all these cases, a hupK-like gene was identified in the DNA region between hupF and hypC (Table 1) suggesting a structure for hydrogenase gene clusters similar to that described for $R$. leguminosarum [15]. Interestingly, all organisms encoding the three HupF, HypC and HupK proteins were able to express hydrogenase in the presence of oxygen. Anaerobic bacteria (sulphate-reducers and other anaerobes) encoded only one hypC/hupF-like gene, and no hupK-like gene, and the same situation was found in Enterobacteriaceae.

The availability of the 3D structure of HypC from Thermococcus kodakarensis [25] allowed us to model both $R$. leguminosarum HypC and HupF proteins on that template (Figure 1A). We found that the model derived for HupF is compatible with a structure highly similar to that of $\mathrm{HypC}$, except for the C-terminal domain present only in HupF (Figure 1C). This structural similarity suggests a related function for both proteins.

We used the hupF/hypC sequences identified above to build a phylogenetic tree for this group of proteins (Figure 1B). In this tree we included the sequences corresponding to $h u p F$ and $h y p C$ genes shown in Table 1, along with sequences from HupF/HypC-like proteins 
Table 1 Location of genes encoding HupL, HupF, HupK, and HypC proteins in genomes from Proteobacteria

\begin{tabular}{|c|c|c|c|c|c|}
\hline \multirow[t]{2}{*}{ Bacterial species } & \multirow[t]{2}{*}{$\#^{a}$} & \multicolumn{4}{|c|}{$\mathrm{KEGG}^{\mathrm{b}}$ Locus designation for homolog to } \\
\hline & & HupL & HupF & HupK & HypC \\
\hline Alkalimnicola ehrlichei & 1 & Mlg_2028 & Mlg_2025 & Mlg_2020 & Mlg_2016 \\
\hline Azoarcus sp. BH72 & 2 & azo3787 & azo3793 & azo3798 & azo3802 \\
\hline Azotobacter vinelandii & 3 & Avin_50580 & Avin_50550 & Avin_50500 & Avin_50460 \\
\hline Beijerinckia indica & 4 & Bind_1151 & Bind_1154 & Bind_1158 & Bind_1162 \\
\hline Bradyrhizobium sp. ORS278 & 5 & BRADO1685 & BRADO1688 & BRADO1693 & BRADO1698 \\
\hline Bradyrhizobium japonicum USDA110 & 6 & bs16941 & bsl6938 & bll6933 & bs16929 \\
\hline Bradyrhizobium sp. BTAi1 & 7 & BBta_1997 & BBta_2000 & BBta_2005 & BBta_2009 \\
\hline Burkholderia vietnamiensis & 8 & Bcep1808_5932 & Bcep1808_5935 & Bcep1808_5940 & Bcep1808_5944 \\
\hline Burkholderia phymatum & 9 & Bphy_7264 & Bphy_7261 & Bphy_7257 & Bphy_7253 \\
\hline Dechloromonas aromatica & 10 & Daro_3988 & Daro_3985 & Daro_3980 & Daro_3967 \\
\hline Magnetococcus sp. & 11 & Mmc1_2503 & Mmc1_2501 & Mmc1_2497 & Mmc1_2490 \\
\hline Magnetospirillum magneticum & 12 & amb1647 & amb1645 & amb1644 & amb1640 \\
\hline Methylibium petroleiphilum & 13 & Mpe_A2826 & Mpe_A2821 & Mpe_A2817 & Mpe_A2813 \\
\hline Paracoccus denitrificans & 14 & Pden_3098 & Pden_3102 & Pden_3106 & Pden_3110 \\
\hline Polaromonas naphtalenivorans & 15 & Pnap_1974 & Pnap_1970 & Pnap_1965 & Pnap_1961 \\
\hline Ralstonia metallidurans & 16 & Rmet1297 & Rmet1292 & Rmet1287 & Rmet1283 \\
\hline Rhodobacter sphaeroides ATCC17029 & 17 & Rsph17029_2147 & Rsph17029_2151 & Rsph17029_2155 & Rsph17029_2159 \\
\hline Rhodoferax ferrireducens & 18 & Rfer_4091 & Rfer_4093 & Rfer_4118 & Rfer_4098 \\
\hline Rhodopseudomonas palustris & 19 & RPA0963 & RPA0967 & RPA0972 & RPA0976 \\
\hline Rhodospirillum rubrum ATCC11170 & 20 & Rru_A1162 & Rru_A1165 & Rru_A1167 & Rru_A0307 \\
\hline Xanthobacer autotrophicus & 21 & Xaut_2174 & Xaut_2177 & Xaut_2181 & Xaut_2185 \\
\hline
\end{tabular}

Taken from KEGG gene database (http://www.genome.jp/kegg/genes.html).

${ }^{b}$ Ordinal numbers used in phylogenetic tree of Figure 1.

from the well studied hydrogenase systems from $R$. leguminosarum and R. eutropha. Analysis of this phylogenetic tree revealed that HupF clusters as a coherent branch separated from HypC, suggesting a divergent evolution from a common ancestor driven by selection for potential functional differences of the two proteins.

\section{HupF is required for hydrogenase activity}

Previous transposon mutagenesis of the $R$. leguminosarum hydrogenase region did not result in insertions located in hupF $[28,29]$. In order to test the essentiality of this gene for hydrogenase activity we analyzed the hydrogenase activity associated to cosmid pALPF5, a pALPF1 derivative harboring the hup/hyp gene cluster with a precise deletion on hupF gene (see Methods). In these experiments, microaerobic $\left(1 \% \mathrm{O}_{2}\right)$ cultures of the hup-complete strain UPM 1155(pALPF1) showed high levels of hydrogenase activity, whereas the hupF-deleted strain UPM 1155(pALPF5) showed only basal levels of activity similar to those observed for the hypC-deleted strain UPM1155(pALPF14) used as negative control (Table 2). The $\triangle h u p F$ mutant was fully complemented by plasmid pPM501, encoding a HupF protein
C-terminally fused to a Strep TagII affinity tail $\left(\mathrm{HupF}_{\mathrm{ST}}\right.$ see Methods section). These data also indicate that $\mathrm{HupF}_{\mathrm{ST}}$ is fully functional.

\section{HupF contributes to HupL stability under elevated oxygen tensions}

The existence of $h u p F$ in hydrogenase systems from bacteria synthesizing this enzyme in the presence of oxygen prompted us to study the potential role of this protein in protection against oxygen. To this aim, we analyzed the possible effect of HupF on the status of hydrogenase large subunit in cultures maintained under different oxygen tensions ( $1 \%$ and $3 \%)$. The higher oxygen tension (3\%) still allowed the expression of hydrogenase in $R$. leguminosarum wild-type strain, although at a reduced level $\left(40 \%\right.$ of the level induced under $1 \% \mathrm{O}_{2}$, Table 2). The presence and processing status of the hydrogenase large subunit (HupL) were analyzed in crude cell extracts from microaerobic cultures through immunoblot (Figure 2). In these experiments we found that the wild-type cells contained a clear band associated to the mature form of HupL, irrespective of whether cells were induced under $1 \%$ or $3 \%$ oxygen (Figure $2 \mathrm{~A}$ and $2 \mathrm{~B}$, 


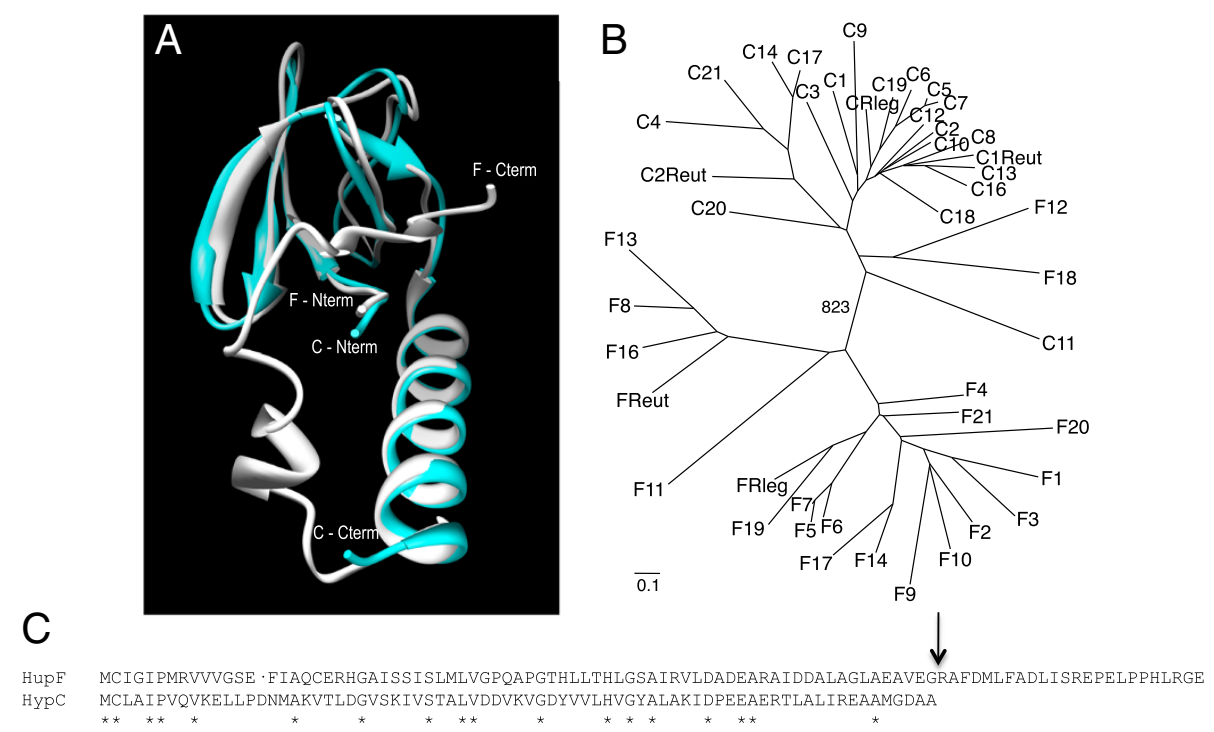

Figure 1 Structural, phylogenetic, and sequence comparisons of HupF and HypC. A) Overlay of HupF (white) and HypC (blue) predicted structures. Structural predictions were carried out with the UCSF Chimera package from the Resource for Biocomputing, Visualization, and Informatics at the University of California, San Francisco ([26]; supported by NIH P41 RR001081), and were based on the structure of Thermococcus kodakarensis HypC (PDB 2z1c) and on ab initio predictions using the I-TASSER server [27]. Positions of $\mathrm{N}$ - and C-termini of each protein are indicated. B) Neighbour-joining phylogenetic tree of HupF and HypC. Sequences derived from the hupF and hypC genes listed in Table 1, along with those from R. leguminosarum (FRleg and CRleg) and R. eutropha (FReut, C1Reut, and C2Reut), were aligned with ClustalX, and the alignment was corrected for multiple substitutions and refined manually. Distances were generated with the same program using the neighbour-joining method, and bootstrapped (1000x). TREEVIEW was used to draw the most likely tree. Sequence names shown in the tree contain a first letter

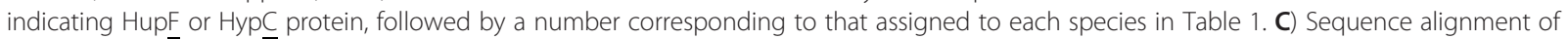
R. leguminosarum HupF and HypC proteins. Alignment was carried out on a structural basis using I-TASSER. Asterisks indicate conserved residues. Vertical arrow indicates the start point for the C-terminal deletion in HupF $\mathrm{CST}_{\text {. }}$

upper panel). This band was absent in a $\Delta$ hupL mutant used as negative control (Figure 2A). Analysis of the cell extracts from the $\triangle h u p F$ strain grown at $1 \%$ oxygen revealed the presence of HupL, although in the unprocessed form (Figure 2A, upper panel). Interestingly, HupL was not detected when cultures from the same mutant strain were incubated under $3 \% \mathrm{O}_{2}$ (Figure 2B). In contrast, extracts from a $R$. leguminosarum mutant lacking HypC, used as a hydrogenase non-processing control, showed a clear band of unprocessed HupL after exposure to both $1 \%$ and $3 \%$ oxygen tension (Figure $2 \mathrm{~A}$ and $2 \mathrm{~B}$ ). Similar levels of an immunoreactive band corresponding to HypB were detected in all the extracts (Figure 2, lower panels), indicating that the microaerobic induction of
Hup expression was equally effective for all strains in each treatment. These data suggest that, in the presence of $3 \%$ oxygen, HupL is either unstable or not synthesized in the absence of HupF. In order to further evaluate these possibilities, we analyzed the in vivo stability of HupL as a function of the presence/absence of HupF. To address this question, we first induced $R$. leguminosarum cultures for hydrogenase expression under $1 \%$ oxygen, and then the induced cells, carrying either processed HupL (wildtype strain) or unprocessed HupL ( $\triangle h u p F$ and $\triangle h y p C$ mutants), were exposed to atmospheres containing either $1 \% \mathrm{O}_{2}$ or $21 \% \mathrm{O}_{2}$ for up to 3 hours. After such treatments, the amount and processing status of HupL was determined through immunoblot assay in cell extracts

Table 2 Hydrogenase activity induced by $R$. leguminosarum strains in microaerobic cultures and in pea bacteroids

\begin{tabular}{|c|c|c|c|c|}
\hline \multirow[t]{2}{*}{ Strain } & \multirow[t]{2}{*}{ Genotype } & \multicolumn{3}{|c|}{ Hydrogenase activity $^{a}$} \\
\hline & & $1 \% \mathrm{O}_{2}$ & $3 \% \mathrm{O}_{2}$ & Bacteroids \\
\hline UPM1155(pALPF1) & wild type & $13440 \pm 1720$ & $4970 \pm 472$ & $5980 \pm 852$ \\
\hline UPM1155 (pALPF14) & $\Delta$ МypC & $<200$ & $<200$ & $<200$ \\
\hline UPM1155 (pALPF5) & $\Delta h u p F$ & $<200$ & $<200$ & $470 \pm 84$ \\
\hline UPM1155 (pALPF5/pPM501) & $\Delta h u p F / h u p F_{\mathrm{ST}}$ & $12890 \pm 230$ & $5900 \pm 779$ & $5350 \pm 728$ \\
\hline UPM1155(pALPF5/pPM501C) & $\Delta h u p F / h u p F_{\text {CST }}$ & $4780 \pm 228$ & $1025 \pm 255$ & $5400 \pm 683$ \\
\hline
\end{tabular}

Values, expressed in nmoles $\mathrm{H}_{2} \mathrm{~h}^{-1}$ (mg protein) ${ }^{-1}$, are the average of three independent assays $\pm \mathrm{SE}$. 


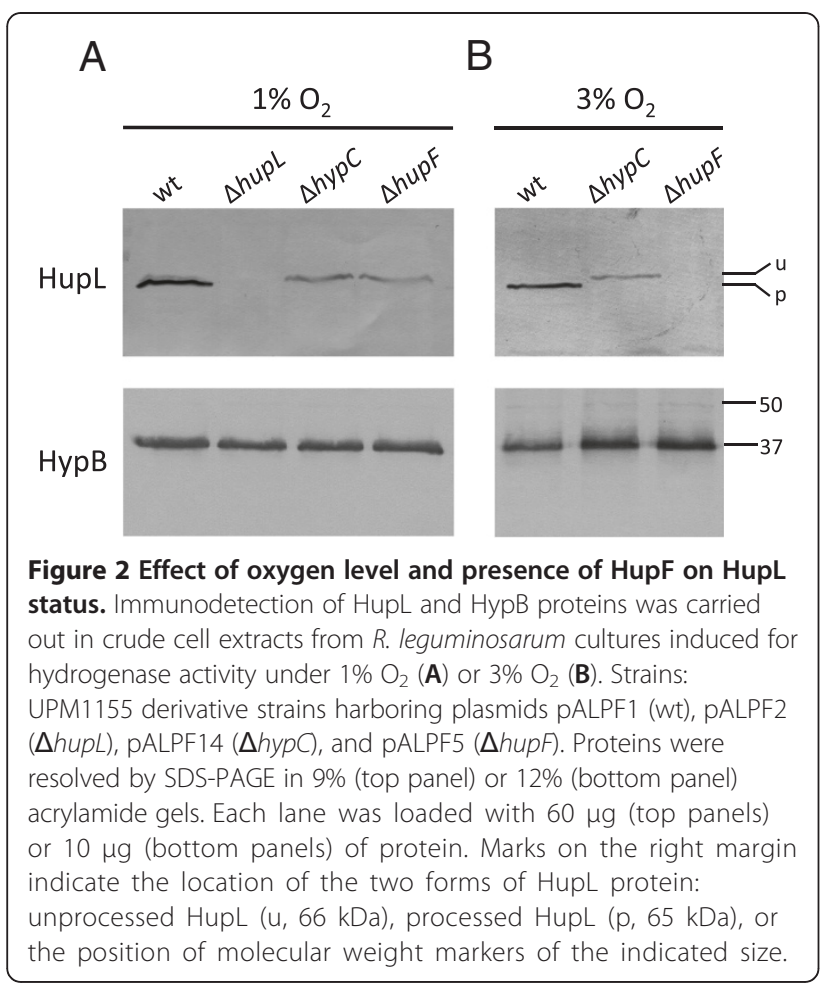

(Figure 3A). The result of these experiments revealed that, as expected, the level of HupL was not significantly altered by incubation under $1 \% \mathrm{O}_{2}$ in all the strains tested. Also, incubation of wild-type cells under $21 \%$ oxygen revealed that the mature form of hydrogenase large subunit was fully stable under these conditions. In contrast, incubation of $\triangle h u p F$ cultures under $21 \% \mathrm{O}_{2}$ resulted in the gradual disappearance of unprocessed HupL, virtually undetectable after $3 \mathrm{~h}$, whereas the unprocessed form in the $\triangle h y p C$ mutant was significantly more stable upon incubation under $21 \%$ oxygen. A similar analysis performed with an anti-HypB antiserum, used as control, revealed that the levels of this protein were stable during the incubation, irrespective of whether cells were incubated under $1 \%$ or $21 \% \mathrm{O}_{2}$ (Figure 3B).

\section{HupF participates in protein complexes with HupL and HupK during hydrogenase biosynthesis}

The observed role of HupF on stabilization of HupL in the presence of oxygen prompted us to examine the existence of interactions between both proteins. We studied such interactions through pull-down experiments with soluble extracts from $R$. leguminosarum cultures expressing $\mathrm{HupF}_{\mathrm{ST}}$ from plasmid pPM501. In this plasmid the expression of $h u p F_{\mathrm{ST}}$ is under the control of the same $\mathrm{P}_{\text {fixN }}$ promoter used for the remaining hup/hyp genes in pALPF1. In order to "freeze" intermediate complexes produced during the biosynthetic process, this plasmid was expressed in strain UPM 1155(pALPF4), carrying an in-frame deletion in the gene ( $h u p D)$ for the protease involved in the final step of HupL maturation.

Soluble fractions from $R$. leguminosarum UPM 1155 (pALF4, pPM501) cultures grown under microaerobic conditions $\left(1 \% \mathrm{O}_{2}\right)$ were loaded into Strep Tactin columns, and desthiobiotin-eluted fractions were separated by SDS-PAGE and analyzed through immunoblot (Figure 4, upper panels). When membranes were probed with StrepTactin-AP conjugate, a strong band of the expected size for $\mathrm{HupF}_{\mathrm{ST}}$ (ca. $10 \mathrm{kDa}$. Figure 4B) was detected, indicating that the system was efficient in recovering this protein. Similar immunoblots were developed with an anti-HupL antiserum. In these experiments we found in the eluates a strong immunoreactive band of a size corresponding to the unprocessed form of
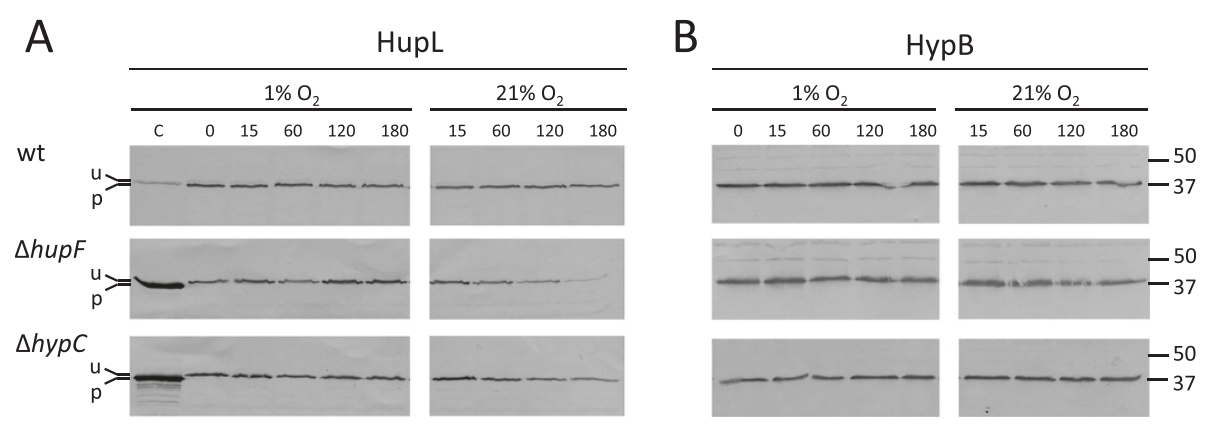

Figure 3 Effect of HupF on HupL stability under high oxygen tensions. Time course of immunodetection of HupL (panel $\mathbf{A}$ ) and HypB (panel B) proteins in cell crude extracts from cultures previously induced for hydrogenase activity and then bubbled with $1 \% \mathrm{O}_{2}$ or air $\left(21 \% \mathrm{O}_{2}\right)$ for the indicated periods of time ( $\mathrm{min}$ ). Top, medium, and bottom panels correspond to cell extracts from R. leguminosarum UPM1155 derivative strains harboring plasmids pALPF1 (wt), pALPF5 ( $\triangle$ hupF), and PALPF14 ( $\triangle$ hypC), respectively. Conditions of SDS-PAGE and loading are as in Figure 2. Lanes labelled as 0 contain control crude extracts harboring either unprocessed HupL from UPM1155(pALPF14) ( $\Delta$ hypC), in top panel, or processed HupL from UPM1155(pALPF14) (wt), in medium and bottom panels as controls. Marks on the left margins indicate the position of the unprocessed $(u, 66 \mathrm{kDa})$ and processed $(\mathrm{p}, 65 \mathrm{kDa})$ forms of HupL in panel $\mathrm{A}$, and marks on the right margins indicate the position of molecular weight markers. 


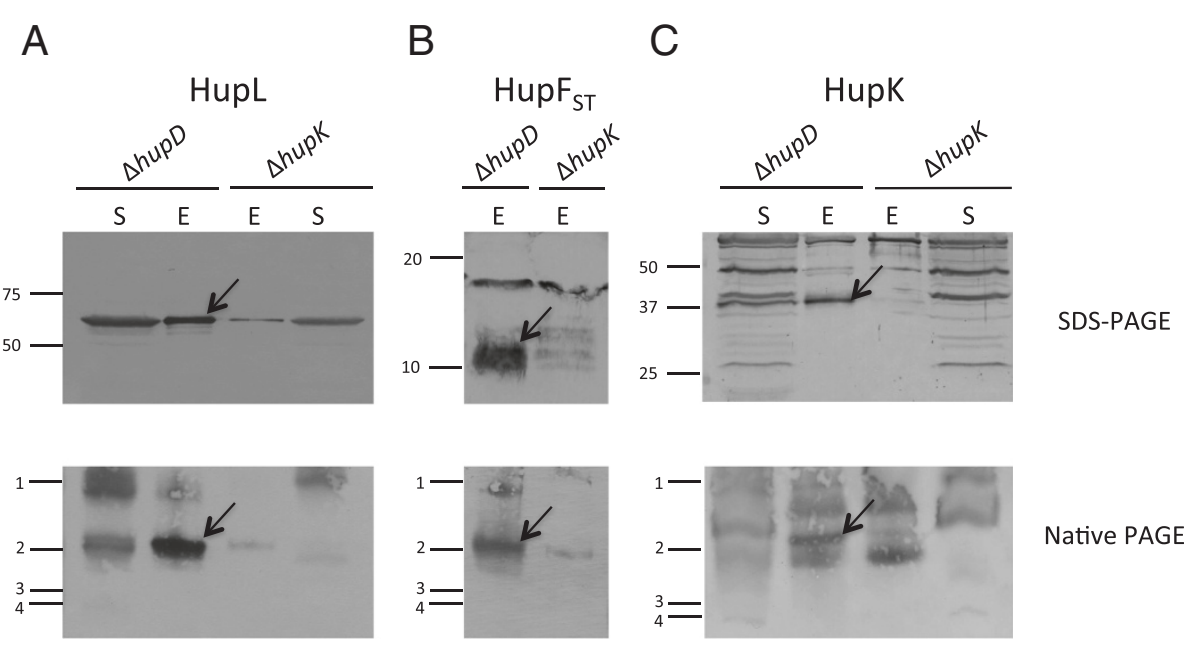

Figure 4 Pull-down analysis of HupF interactions with HupL and HupK proteins. Proteins were resolved by SDS-PAGE (top panels) or 4-20\% gradient native PAGE (bottom panels). Immunoblots were revealed with antisera raised against HupL (panel A) or HupK (panel C), or with StrepTactin-alkaline phosphatase conjugate (panel B) to detect HupF $F_{S T}$. Eluates (E) were obtained from extracts from R. leguminosarum UPM 1155

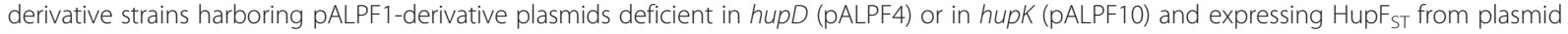
pPM501. Soluble extracts (S) of the corresponding cultures were loaded as controls for detection of HupL and HupK proteins. Arrows indicate the relevant bands identified in the eluate from the $\triangle$ hupD mutant. Proteins subjected to SDS-PAGE (top panels) were loaded in gels with different amounts of polyacrylamide ( $9 \%$ for HupL, $15 \%$ for $\mathrm{HupF}_{\mathrm{ST}}$, and 12\% for HupK). Numbers on the left margin of the panels indicate the position of molecular weight standards ( $\mathrm{kDa}$, top panels), or the position of BioRad Precision Plus Standards (1, $250 \mathrm{kDa}$; 2, 150 kDa, 3, 75 kDa; 4, 100 kDa) in native gels (bottom panels).

the hydrogenase large subunit (ca. $66 \mathrm{kDa}$, Figure 4A). This band could be detected also in the soluble extract. The co-purification of this protein along with $\mathrm{HupF}_{\mathrm{ST}}$ suggests the existence of a complex between HupF and HupL.

Immunoblot analysis was also carried out with an anti-HupK antiserum (Figure 4C). This analysis identified several immunoreactive bands in the soluble fraction of the $\triangle h u p D$ mutant, one of which likely corresponded to HupK, since it showed the expected molecular size ( $c a$. $37 \mathrm{kDa}$ ) for this protein, and was absent in the extract from the $\Delta$ hupK mutant. Analysis of the Strep Tactin eluates with the same antiserum revealed that the same specific band co-eluted with $\mathrm{HupF}_{\mathrm{ST}}$ in the $\Delta$ hupD mutant, but was absent in the eluate from the hupK-deficient strain, strongly suggesting the existence of a complex involving HupF and HupK. It has to be noted that eluates obtained from the hupK-deficient mutant contained reduced levels of $\mathrm{HupF}_{\mathrm{ST}}$ (and hence, of coeluted HupL), suggesting that $\mathrm{HupF}$ might require the presence of HupK for full stability (Figure 4A and 4B).

In order to obtain additional confirmation for the existence of the complexes deduced from the pull-down experiments described above, the eluates were further analyzed using non-denaturing conditions. To this aim, the immunoblot analysis was repeated after the proteins eluted from Strep Tactin columns were resolved in 4-20\% gradient polyacrylamide native gels (Figure 4, lower panels). When the immunoblot was developed with anti-
HupL antiserum, a major immunoreactive band was detected in eluates from the $\triangle h u p D$ derivative strain (Figure 4A). A band of similar size and mobility was detected when a replicate immunoblot was developed with the Strep Tactin-AP conjugate (Figure 4B), suggesting that both bands correspond to a HupL-HupF complex. In both cases, the absence of HupK was associated

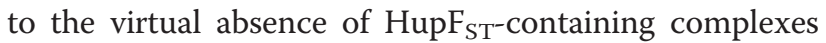
(Figure 4A and 4B). Finally, a third replicate of the same immunoblot developed with the anti-HupK antiserum revealed a fainter band, with a slightly lower mobility (Figure 4C), suggesting a different, less abundant HupKHupF complex. As before, non-specific bands were detected by this antiserum in the $\Delta h u p K$ mutant, likely corresponding to complexes of the non-specific bands detected in the SDS-PAGE experiments described above.

Further confirmation on the composition of the complex or complexes detected by immunoblotting was sought by peptide mass fingerprinting analysis of the major complex present in the eluate obtained from the $\triangle$ hupD strain UPM 1155(pALPF4, pPM501). Such eluate was resolved by $4-20 \%$ gradient native PAGE, followed by Coomassie Blue staining. In this gel we identified a clear band with a mobility similar to that of the complexes identified above (data not shown). This band was excised and subjected to MALDI-TOF analysis after trypsin digestion. The analysis led to the identification of peptides corresponding to proteins HupL and HupF (data not shown), indicating the 
presence of a major complex involving these two proteins. In this analysis no peptides corresponding to HupK, nor to any other Hup/Hyp proteins, were detected. Taken together, data from immunoblot and mass spectrometry analyses suggest the presence of two different complexes: a major complex containing HupF and HupL, and a second, much less abundant complex involving $\mathrm{HupF}$ and $\mathrm{HupK}$, only detectable through immunoblot analysis.

\section{Functional analysis of the HupF C-terminal region}

A distinctive domain of $R$. leguminosarum HupF is the extended $\mathrm{C}$-terminal region, absent in the otherwise structurally related HypC protein (Figure 1). In order to elucidate the relevance of this region for HupF function, we constructed plasmid pPM501C, a pPM501 derivative in which the hupF gene was modified to produce a truncated version of $\mathrm{HupF}_{\mathrm{ST}}\left(\mathrm{HupF}_{\mathrm{CST}}\right)$ with a precise deletion of the $\mathrm{C}$-terminal 24 amino acid residues of $\mathrm{HupF}$ (see Methods). When this plasmid was introduced into the HupF-deficient strain UPM 1155(pALPF5), only partial restoration of hydrogenase activity (37\%) was observed under standard inducing conditions $\left(1 \% \mathrm{O}_{2}\right.$, Table 2) and, consistently, the amount of processed protein was significantly reduced (Figure 5A, top panel). These data indicate that the truncated form of the protein is partially impaired in its role when hydrogenase biosynthesis is carried out in an atmosphere of $1 \% \mathrm{O}_{2}$. Since HupF was shown to contribute to HupL stability under higher oxygen tensions (Figure 2), we also tested the effect of the C-terminal deletion under these conditions. Interestingly, when hydrogenase was induced in an atmosphere containing 3\% oxygen, the truncated form of the protein supported only $17 \%$ of the activity associated to the complete form of the protein (Table 2), which corresponded to virtually undetectable amounts of processed HupL protein (Figure 5B, top panel). Since the evidence pointed towards a more relevant role for the C-terminal region of HupF under higher oxygen tensions, we hypothesized that such an effect should be less relevant under symbiotic conditions. Bacteroids within the legume nodule are maintained under oxygen tensions in the nanomolar range [30], at least three orders of magnitude lower than those present in microaerobic cultures. We determined hydrogenase activity and HupL processing in pea bacteroids induced by $R$. leguminosarum strains carrying either the whole or the truncated version of HupF. In this experiment, both forms of the protein complemented the $\triangle h u p F$ mutant to wild-type levels of activity, irrespective of the presence of the C-terminal region (Table 2). Also, immunoblot analysis of bacteroid crude extracts indicated that the level of HupL processing was not significantly altered by the deletion (Figure $5 \mathrm{C}$ ). These data indicate that the $\mathrm{C}$-terminal region of the protein is not required at ultra-low oxygen tensions.

\section{Discussion}

The maturation of metalloenzymes such as [NiFe] hydrogenase requires the biosynthesis and insertion of metal cofactors through the action of auxiliary proteins. The soluble, hydrogen-evolving hydrogenase-3 enzyme from $E$. coli has served as a model to elucidate the intricate biosynthetic pathway for the [NiFe] cofactor [2]. However, there is increasing evidence indicating that the model for biosynthesis of this cofactor might not be universal [20]. Ancient enzymes such as hydrogenase had to evolve to accommodate into an $\mathrm{O}_{2}$-containing environment. From a biotechnological point of view, oxygen tolerance is a relevant characteristic with obvious

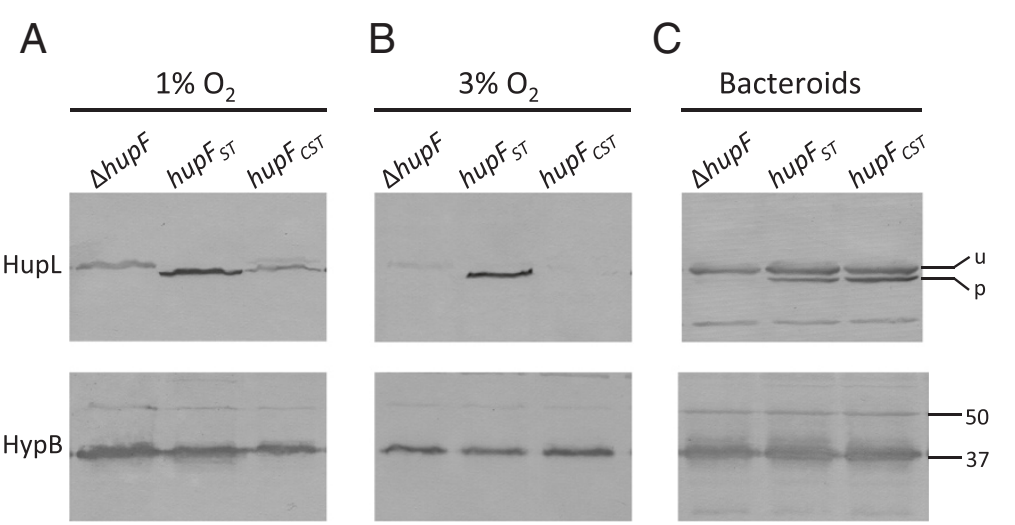

Figure 5 Effect of a C-terminal deletion on HupF in R. leguminosarum hydrogenase processing. Immunodetection of hydrogenase large subunit HupL (top panels) and HypB (bottom panels) was carried out in crude extracts from vegetative cells induced for hydrogenase activity under different oxygen tensions (1\% or 3\%), and in bacteroid crude extracts. Strains: R. leguminosarum UPM1 155 derivatives carrying plasmids

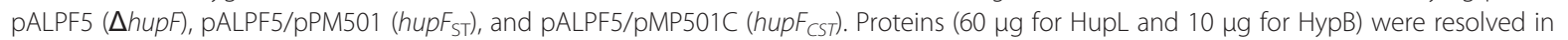
9\% (HupL) or 12\% (HypB) acrylamide SDS-PAGE gels. 
interest [31]. The initial model described for the oxygensensitive hydrogenase from Desulfovibrio gigas [32] has been enriched by recent crystal structures of oxygen tolerant hydrogenases from Hydrogenovibrio marinus, $R$. eutropha, and E. coli, showing that in the case of oxygen-tolerant enzymes, the iron-sulfur cluster proximal to NiFe cofactor corresponds to an unprecedented [4Fe3S] type coordinated with six cysteines [33-35]. This cluster provides redox protection to the NiFe cofactor, by allowing the enzyme to catalyze reduction of $\mathrm{O}_{2}$ to water "in situ" as well as the oxidation of hydrogen. An oxidative environment may also require protection during enzyme biosynthesis. From a genetic point of view, a relevant variation lies in the presence of two additional genes, hupF and hupK and their homologues, encoding auxiliary proteins in hydrogenase systems from aerobic bacteria. Using a specific deletion mutant we have shown in this work that HupF is essential for hydrogenase activity in $R$. leguminosarum, as it has been described in the $R$. eutropha system [20]. The results obtained here indicate that HupF has a dual role during hydrogenase biosynthesis: it is required for hydrogenase large subunit processing and also acts as a chaperone to stabilize HupL when hydrogenase is synthesized in the presence of oxygen.

Data from experiments on exposure of HupLcontaining cells to different oxygen tensions indicate that, in the absence of HupF, unprocessed HupL gradually disappears at high oxygen tensions. Since there is no $\mathrm{P}_{\text {fix } N^{-}}$driven expression of hupL at $21 \% \mathrm{O}_{2}$ [18], the decrease in the level of HupL is likely due to a loss of stability of the protein.

Analysis of the C-terminal deletion mutant of HupF suggests that this domain might be relevant for HupL stabilization and might provide additional support for the role of HupF as an oxygen protective chaperone. The C-terminally truncated protein is functionally indistinguishable from the full-size protein under symbiotic, ultra-low oxygen conditions, whereas the functionality of the truncated protein is increasingly compromised in free-living cells under $1 \%$ and $3 \% \mathrm{O}_{2}$. Preliminary analysis of the mutant protein indicates that it still binds HupL, although at lower level, whereas it appears as fully competent in HupK binding (data not shown).

The results presented in this work indicate the existence of physical interactions between HupF, HupK, and HupL during biosynthesis of the hydrogenase large subunit in $R$. leguminosarum. This subunit contains cysteine motifs involved in the binding of the NiFe cluster [1]. The identification of similar motifs in HupK-like proteins had led to the hypothesis of a scaffolding role for HupK similar to that of NifE protein in nitrogenase synthesis [36]. Experimental evidence showed that HoxV, the HupK homolog in the $R$. eutropha system, was indeed able to bind the cofactor precursor with the cyano- and carbonyl ligands bound to a Fe atom, thus assigning a key role to this protein in the incorporation of the cofactor into hydrogenase [20]. In the same system, the existence of HoxL-HoxG and HypCHoxV complexes was inferred from SDS-PAGE analysis of proteins obtained in co-purification experiments [20]. The data from immunoblot analysis under native conditions and from mass spectrometry analysis presented here provide a direct evidence of the existence of two such complexes in $R$. leguminosarum: a major HupLHupF complex and a much less abundant one involving HupF and HupK. The high recovery of HupL with $\mathrm{HupF}_{\mathrm{ST}}$ points towards a strong interaction between both proteins in the $\Delta h u p D$ mutant, where the NiFe cofactor is supposed to be inserted into HupL but the protein is still unprocessed. In this situation HupF is firmly attached to unprocessed HupL, and we hypothesize that this immature protein might require the oxygenprotective function of $\mathrm{HupF}$ to protect the labile NiFe cluster prior to proteolytic processing, when the protein is still in an open conformation. Following the model described for the $R$. eutropha system [24] we propose that $R$. leguminosarum proteins in these complexes interact to transfer the iron-containing hydrogenase cofactor precursor from HupK to HupL, prior to the final HupDmediated proteolytic step. But HupF protein also contributes to the stability of hydrogenase large subunit at high oxygen tensions. Data from experiments performed in a $\Delta$ hupS background indicate that HupF is not bound to HupL after HupD-mediated proteolytic processing (our unpublished results), indicating that mature HupL is stable enough to not require any additional chaperones, as suggested also by the results on stability of mature enzyme under $21 \% \mathrm{O}_{2}$ presented in this paper. This model might not be the only possibility for the biosynthesis of oxygen-tolerant hydrogenases, since recent evidences indicate that hydrogenase- 1 from this $E$. coli is an oxygentolerant hydrogen uptake hydrogenase [37], and neither HupF- nor HupK-like proteins are present in this bacterium.

Previous data from our lab and from other laboratories suggest that adaptations to the presence of oxygen also exist for the synthesis of hydrogenase small subunit HupS through the participation of HupGHIJ proteins or their homologues $[19,38]$. In the case of endosymbiotic bacteria, such as R. leguminosarum, the synthesis of hydrogenase under the ultra-low oxygen tensions prevalent in symbiotic conditions is less severely dependent on such auxiliary proteins [19]. The low, although significant, levels of hydrogenase activity detected in bacteroids induced by the $\triangle h u p F$ mutant, but not in vegetative cells, might indicate that for $R$. leguminosarum this major HypC $\rightarrow$ HupK $\rightarrow$ HupF $\rightarrow$ HupL pathway for cofactor 
transfer might coexist in bacteroids with a low level of alternative biosynthesis, perhaps via the direct $\mathrm{HypC} \rightarrow \mathrm{HupL}$ mode established for E. coli [2].

The assembly and incorporation of non-protein ligands is a critical aspect in hydrogenase synthesis for which we still have a limited knowledge. The newly described role for HupF in this process is probably one of the adaptations to the presence of oxygen, a condition that likely affected the evolutionary history of this metalloenzyme originated in an ancient, mainly anaerobic period of the biosphere. A better understanding of the molecular basis of these adaptations will hopefully allow the design of oxygen tolerant hydrogenase enzymes for biotechnological purposes.

\section{Conclusions}

Analysis of mutants induced for hydrogenase activity under different conditions indicate that HupF has a dual role during hydrogenase biosynthesis: it is required for hydrogenase large subunit processing, and also acts as a chaperone to stabilize HupL when hydrogenase is synthesized in the presence of oxygen. The HupF-HupL and HupF-HupK complexes identified in pull-down experiments and mass spectrometry analysis are likely involved in such functions.

\section{Methods}

Bacterial strains, plasmids, and growth conditions

Strains and plasmids used in this study are listed in Table 3. $R$. leguminosarum strains were routinely grown at $28^{\circ} \mathrm{C}$ in YMB [39]. E. coli DH5 $\alpha$ was used for standard cloning procedures and E. coli S17.1 for conjugative plasmid transfer between $E$. coli and $R$. leguminosarum. Antibiotic concentrations used were as follows $\left(\mu \mathrm{g} \mathrm{ml}^{-1}\right)$ : ampicillin, 100; kanamycin, 50; tetracycline, 5 (for $R$. leguminosarum) or 10 (for E. coli).

\section{Plant tests}

Pea (Pisum sativum L. cv. Frisson) seeds were surfacedisinfected, pregerminated on agar plates, sown in Leonard jar-type assemblies, and inoculated with $R$. leguminosarum bv. viciae strains, as previously described [45]. Plants were grown for 21 days under bacteriologically controlled conditions with a nitrogen-free plant nutrient solution in a greenhouse adjusted to $18 / 25^{\circ} \mathrm{C}$

Table 3 Bacterial strains and plasmids used in this work

\begin{tabular}{|c|c|c|}
\hline Strain or plasmid & Relevant genotype or phenotype & Source or reference \\
\hline \multicolumn{3}{|l|}{$\begin{array}{l}\text { Rhizobium } \\
\text { leguminosarum }\end{array}$} \\
\hline UPM791 & 128C53 wild type; $\mathrm{Str}^{\mathrm{r}} \mathrm{Nod}^{+} \mathrm{Fix}^{+} \mathrm{Hup}^{+}$ & [40] \\
\hline UPM1155 & UPM791 ( $\Delta$ hup/hyp cluster) Hup ${ }^{-}$ & {$[19]$} \\
\hline \multicolumn{3}{|l|}{ Escherichia coli } \\
\hline $\mathrm{DH} 5 \mathrm{a}$ & recA1 endA1 gyrA96 thi hsdR17 supE44 relA1 $\Delta$ (lacZYA-argF)U169 Ф80dlacZDM15 & {$[41]$} \\
\hline S17.1 & thi pro hsdR $h s d M^{+}$recA RP4::2-Tc::Mu-Kan::T7; $\left(\mathrm{Sp}^{r} \mathrm{Sm}^{r}\right)$ & {$[42]$} \\
\hline \multicolumn{3}{|l|}{ Plasmids } \\
\hline pAL618 & pLAFR1-based cosmid containing the whole $R$. leguminosarum hydrogenase gene cluster & {$[40]$} \\
\hline pALPF1 & pAL618 with hupSL promoter replaced by fixN promoter $\left(P_{f i x N}\right)$ & [18] \\
\hline PALPF2 & pALPF1 $\Delta$ hupl & {$[19]$} \\
\hline PALPF4 & pALPF1 $\triangle h u p D$ & {$[19]$} \\
\hline pALPF5 & pALPF1 $\triangle h u p F$ & This work \\
\hline PALPF10 & pALPF1 $\Delta$ hupK & This work \\
\hline pALPF14 & pALPF1 $\Delta h y p C$ & This work \\
\hline pALPF382 & pALPF1 derivative carrying hupF $F_{S T}$ gene & This work \\
\hline pBBR1MCS-2 & Broad-host-range plasmid; $\mathrm{Km}^{\mathrm{r}} \mathrm{mob}^{+}$ & [43] \\
\hline pKD3 & Template plasmid harbouring FLP-mediated excision sequences flanking $\mathrm{Cm}^{\mathrm{r}}$ gene & [44] \\
\hline pPM71 & PKD3 derivative containing Strep-tag II sequence for C-terminal end fusion & This work \\
\hline pPM1350 & $\begin{array}{l}\text { pBBR1MCS-2 derivative containing a DNA fragment harbouring } P_{f i x N} \text { promoter from } R \text {. } \\
\text { leguminosarum }\end{array}$ & {$[19]$} \\
\hline pPM501 & $\begin{array}{l}\text { PPM1350 derivative containing an Ndel-Xbal fragment harbouring } \\
\text { HupF } F_{S T} \text { under the control of } P_{\text {fix }}\end{array}$ & This work \\
\hline pPM501C & pPM501 derivative containing a deletion of the $253 /$ codons of hupF & This work \\
\hline PPCR2.1-TOPO & PCR cloning vector & Invitrogen \\
\hline
\end{tabular}


(night/day) temperatures. Nitrogen-free plant nutrient solution was supplemented with $170 \mu \mathrm{M} \mathrm{NiCl}_{2}$ on day 10 after seedling inoculation. Bacteroid suspensions were obtained from nodules as previously described [40].

\section{Hydrogenase activity assays}

Hydrogenase activity in bacteroid suspensions and in free-living microaerobic cell cultures was measured by an amperometric method using a Clark-type electrode with oxygen as electron acceptor [45]. Hydrogenase activity in vegetative cells was induced in $40-\mathrm{ml}$ cultures grown under continuous bubbling with a gas mixture containing $\mathrm{O}_{2}$ concentrations of 1 or $3 \%$ in $\mathrm{N}_{2}$. Strains were aerobically grown in YMB medium to an optical density at $600 \mathrm{~nm}\left(\mathrm{OD}_{600}\right)$ of $c a$. 0.4. From these cultures a 1:4 dilution was made in fresh YMB medium. Flasks were capped with a stoppered-tube system adapted to continuous flushing with $1 \%$ or $3 \% \mathrm{O}_{2}$ on $\mathrm{N}_{2}$, and incubated at $28^{\circ} \mathrm{C}$ for $20 \mathrm{~h}$. For HupL stability studies, bacterial cultures were maintained in a bottle with continuous bubbling with either $1 \% \mathrm{O}_{2}$ or air during 3 hours after standard microaerobic induction $\left(1 \% \mathrm{O}_{2}\right)$. Cell cultures were centrifuged and suspended in $5 \mathrm{ml}$ Dixon buffer (32 $\mathrm{mM} \mathrm{K}_{2} \mathrm{HPO}_{4}, 24 \mathrm{mM} \mathrm{KH}_{2} \mathrm{PO}_{4}$ and $0.24 \mathrm{mM} \mathrm{MgCl}$ ) before amperometric determinations. To prevent damage of hydrogenase due to $\mathrm{O}_{2}$ exposition, extracts were bubbled with argon during preparation. Protein contents of vegetative cells and bacteroids were determined by the bicinchoninic acid method [46] after alkaline digestion of cells at $90^{\circ} \mathrm{C}$ in $\mathrm{NaOH}$ for 10 min, with bovine serum albumin as the standard.

DNA manipulation techniques and mutant construction DNA manipulations, including purification, restriction, ligation, agarose gel electrophoresis, PCR amplification, and transformation into E. coli cells were carried out by standard methods [47].

In-frame deletions of hupF, hupK and hypC genes were generated in plasmid pALPF1 as described by Manyani et al. [19], resulting in plasmids pALPF5, pALPF10, and pALPF14, respectively. Primers used for deletions and plasmid generation are included in Table 4 .

To generate the HupF::Strep TagII $\left(\mathrm{HupF}_{\mathrm{ST}}\right)$ fusion protein, a modification of the Datsenko and Wanner deletion system [44] was used. The modification consisted in insertion of the sequence coding for the StrepTag II peptide (WSHPQFEK) in the 5 'end of the antibiotic resistance gene of the pKD3 plasmid [19] resulting in plasmid pPM71. This plasmid was used as template for in-frame fusing of the Strep Tag II sequence to the $3^{\prime}$ end of hupF from pALPF1 plasmid using TAGF31-TAGF32 by a procedure previously described [19]. The resulting pALPF1 derivative plasmid pALPF382 harbors a hydrogenase gene cluster encoding hupF::Strep Tag II $\left(h u p F_{S T}\right)$.

In order to express $h u p F_{S T}$ gene in microaerobically grown cultures of $R$. leguminosarum in a compatible way with Hup expression from pALPF1 derivatives, a pBBR1MCS derivative plasmid (pPM501) harboring $h u p F_{S T}$ was constructed. To this end we amplified this gene using plasmid pALPF382 as template and FNDEMANG3 primers. Amplified fragment was cloned (NdeI$X b a \mathrm{I})$ in pPM1350 plasmid [19]. This plasmid harbors the $\mathrm{P}_{f i x N}$ promoter from pALPF1 that is expressed in microaerobic conditions under the control of the FnrN protein.

A truncated form of $\mathrm{HupF}_{\mathrm{ST}}$ lacking the C-terminal region $\left(\mathrm{HupF}_{\mathrm{CST}}\right)$ was generated by using plasmid pALPF1 as template for the in-frame deletion of the 25 codons at the 3 ' end of hupF gene. The sequence coding for the Strep TagII peptide was fused in frame to the corresponding site of hupF using primers FNDE and

Table 4 Oligonucleotides used in this work

\begin{tabular}{|c|c|c|}
\hline Primer & Sequence $\left(5^{\prime}-3^{\prime}\right)$ & Use \\
\hline HUPF5 & GCGGCACTGCTGGTCGGCTGAATCACTCCCAAGGCTGAGGTGTAGGCTGGAGCTGCTTC & \multirow[t]{2}{*}{ hupF deletion } \\
\hline HUPF3 & CGGCGGCAATTCCGGCTCGCGGGAAATGAGATCGGCGAACATATGAATATCCTCCTTAGT & \\
\hline HUPK52 & ACATTCCTTCTCGGGGCCGGCACGATAGGGATCGACGTGATTCCGGGGATCCGTCGACC & \multirow[t]{2}{*}{ hupK deletion } \\
\hline HUPK32 & TGCGATAGGCTGCGAGCCTGCCGTCACCGCCGATTTCGAGTGTAGGCTGGAGCTGCTTC & \\
\hline HYPC5 & GAACGAACATGCATCAATCGAGGAGAACCGGACATGTGCATTCCGGGGATCCGTCGACC & \multirow[t]{2}{*}{ hypC deletion } \\
\hline HYPC3 & TCGTCGATATATTCATGCCGCATCTCCCATCGCACGTTGTGTAGGCTGGAGCTGCTTC & \\
\hline TAGF31 & TCCCGCGAGCCGGAATTGCCGCCGCATTTGCGCGGCGAGTGGAGCCACCCGCAGTTCGA & \multirow{2}{*}{$\begin{array}{l}\text { Generation of hup } F_{S T} \\
\text { fusion (pALPF382) }\end{array}$} \\
\hline TAGF32 & GGTGGAAACTCAAATTCCATTTTGGAAGTTCTCTITTCAATATGAATATCCTCCTTAGT & \\
\hline FNDE & CTGTCAGTCGTCATATGTGCATCGGCATTCCCAT & \multirow{2}{*}{$\begin{array}{l}\text { Generation of } \\
\text { pPM501/pPM501C } \\
\text { plasmids }\end{array}$} \\
\hline MANG3 & ACGGCGGCGGGAATGCTC & \\
\hline $\begin{array}{l}\text { HUPF-3413 } \\
\text { L-Strep }\end{array}$ & GAGTACTCTCAGGCGCCTIITCGAACTGCGGGTGGCTCCAGCTAGCTCCCTCCACCGCTTCGGCAAGTCCGGCGAG & $\begin{array}{l}\text { Generation of } \\
\text { pPM501C plasmid }\end{array}$ \\
\hline
\end{tabular}


HUPF-3413 L-Strep. Amplified DNA was cloned in PCR 2.1-TOPO, and the construct was confirmed by sequencing. Then, the DNA region containing the truncated hupF gene $\left(h u p F_{C S T}\right)$ was excised with NdeI and XbaI and cloned downstream the $\mathrm{P}_{f i x N}$ promoter of plasmid pPM1350, resulting in plasmid pPM501C. For this cloning we took advantage of the NdeI site generated with primer FNDE and the XbaI site from plasmid PCR2.1.-TOPO.

\section{Purification of HupF-StrepTag II fusion protein}

Protein purification was carried out from 31 of bacterial cultures of $R$. leguminosarum induced for hydrogenase activity under continuous bubbling with a $1 \% \mathrm{O}_{2}$ gas mixture. $40 \mathrm{ml}$ portions of cultures were centrifuged, and cells were resuspended in $5 \mathrm{ml}$ Dixon buffer and assayed for hydrogenase activity as described before. Cell suspensions and extracts used for protein purification were bubbled with argon to avoid damage of hydrogenase from $\mathrm{O}_{2}$ exposure, and centrifuged at $6000 \mathrm{rpm}$ at $4^{\circ} \mathrm{C}$ for 10 minutes. The pellets were suspended in $2 \mathrm{ml}$ of buffer W (100 mM Tris- $\mathrm{HCl}, \mathrm{pH} 8,150 \mathrm{mM} \mathrm{NaCl}$ ) containing a protease inhibitor mixture (Complete-mini; Roche Diagnostics $\mathrm{GmbH}$ ). Cells were disrupted by three passages using a French pressure cell (SLM Aminco, Silver Spring, MD) at $100 \mathrm{MPa}$ and soluble fractions were cleared from cell debris and membranes by ultracentrifugation at $135,000 \times \mathrm{g}$ at $4^{\circ} \mathrm{C}$ for $1 \mathrm{~h}$. The supernatant (soluble extract) was added to a 0.2-ml Strep Tactin Superflow column (IBA, Göttingen, Germany) operated by gravity flow. The column was washed five times with $400 \mu \mathrm{l}$ of buffer $\mathrm{W}$ to remove unbound proteins, and the tagged protein was eluted by the addition of $600 \mu \mathrm{l}(6 \times 100 \mu \mathrm{l})$ of buffer W supplemented with $2.5 \mathrm{mM}$ D-desthiobiotin. Relevant fractions were pooled and concentrated using a centrifugal filter device (Amicon Ultra $0.5 \mathrm{ml}, 3 \mathrm{~K}$ ).

\section{Western immunoblot and peptide mass fingerprinting}

Proteins were resolved by either standard sodium dodecyl sulfate-polyacrylamide gel electrophoresis (SDS-PAGE) or native PAGE in commercial gradient 4-20\% polyacrylamide gels (Bio-Rad, Hercules, California, USA), and were transferred onto Immobilon-P membrane filters (Millipore, Bedford, MA, USA) as previously described [48]. HupL, HupK and HypB proteins were detected immunologically using antisera raised against $R$. leguminosarum HupL (1:400 dilution), HupK (1:100 dilution) and НypB (1:2,000 dilution). Blots were developed by using a secondary goat anti-rabbit immunoglobulin G-alkaline phosphatase conjugate and a chromogenic substrate (bromochloroindolyl phosphate-nitro blue tetrazolium) as recommended by the manufacturer (Bio-Rad Laboratories, Inc. Hercules,

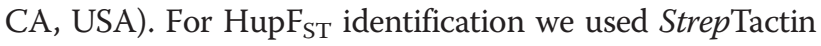

conjugated to alkaline phosphatase (1:2,500; IBA, Göttingen, Germany). Immunoblot analyses were performed with $60 \mu \mathrm{g}$ and $20 \mu \mathrm{g}$ (total protein) of vegetative cells and bacteroids crude extracts, respectively, for HupL, or $10 \mu \mathrm{g}$ for HypB detection. For purification of $\mathrm{HupF}_{\mathrm{ST}}$ protein and study of interactions, immunoblot analysis was performed with $4 \mu \mathrm{g}$ of protein from pooled eluate fractions and $60 \mu \mathrm{g}$ of protein from soluble fraction samples. For identification of complexes by peptide mass fingerprinting, $20 \mu \mathrm{g}$ (total protein) of pooled desthiobiotin-eluted fractions from bacterial cultures of $R$. leguminosarum UPM1155(pALPF4, pPM501) were resolved in native 4$20 \%$ gradient polyacrylamide gels. Then, gels were stained by Coomassie brilliant blue G-250, and bands were excised and sent to the CBGP proteomics facility for analysis by mass spectrometry on a Kratos MALDI-TOF MS apparatus (Kratos Analytical, Manchester) after trypsin digestion. Peptide profile was compared to MASCOT database supplemented with sequences from UPM791 hup/hyp gene products.

\section{Competing interests}

The authors declare that they have no competing interests.

\section{Authors' contributions}

MA carried out most of the experimental work and constructed the C-terminal deletion mutant. HM constructed most of the mutants and plasmids and performed initial analysis of protein-protein interactions. $A B$ conceived the experiments on HupL stability. BB performed experiments with HupF mutant proteins. JI and TRA participated in the design of the study and in the final writing of the manuscript. JP coordinated the study and drafted the manuscript. All authors read and approved the manuscript.

\section{Acknowledgements}

We thank Julia Kehr for her excellent help in protein identification by peptide mass fingerprinting. This work has been funded by research projects from Spain's Ministerio de Ciencia y Tecnología (BIO2010-15301 to J.P.), from Comunidad de Madrid (MICROAMBIENTE-CM to T.R.A.), and from Fundación Ramón Areces (to J.I.). A.B. was the beneficiary of a sabbatical leave at UPM funded by Spain's Ministerio de Educación. M.A. was recipient of an UPMJdC contract co-funded by Universidad Politécnica de Madrid.

\section{Author details}

${ }^{1}$ Centro de Biotecnología y Genómica de Plantas (C.B.G.P.), Universidad Politécnica de Madrid, Campus de Montegancedo, Carretera M40- km 37.7, 28223 Pozuelo de Alarcón, Madrid, Spain. ²Departamento de Biotecnología, Escuela Técnica Superior de Ingenieros, Agrónomos, Universidad Politécnica de Madrid, Ciudad Universitaria s/n, 28040 Madrid, Spain. ${ }^{3}$ Consejo Superior de Investigaciones Científicas (CSIC), Centro de Biotecnología and Genómica de Plantas (C.B.G.P.), Universidad Politécnica de Madrid (U.P.M.), Madrid,

Spain. ${ }^{4}$ Department Biology I, University of Munich, Munich, Germany.

${ }^{5}$ Current address: ResBioAgro, S.L., Centro de Investigación, Tecnología e Innovación, Universidad de Sevilla, 41012 Sevilla, Spain.

Received: 30 August 2012 Accepted: 24 October 2012

Published: 8 November 2012

\section{References}

1. Fontecilla-Camps JC, Volbeda A, Cavazza C, Nicolet Y: Structure/function relationships of [NiFe]- and [FeFe]-hydrogenases. Chem Rev 2007, 107:4273-4303.

2. Böck A, King PW, Blokesch M, Posewitz MC: Maturation of hydrogenases. Adv Microb Physiol 2006, 51:1-71.

3. Vignais PM, Billoud B: Occurrence, classification, and biological function of hydrogenases: an overview. Chem Rev 2007, 107:4206-4272. 
4. Reissmann S, Hochleitner E, Wang H, Paschos A, Lottspeich F, Glass RS, Böck A: Taming of a poison: biosynthesis of the NiFe-hydrogenase cyanide ligands. Science 2003, 299:1067-1070.

5. Shomura Y, Higuchi Y: Structural basis for the reaction mechanism of S-carbamoylation of HypE by HypF in the maturation of [NiFe]hydrogenases. J Biol Chem 2012, 287:28409-28419.

6. Blokesch M, Albracht SPJ, Matzanke BF, Drapal NM, Jacobi A, Böck A: The complex between hydrogenase-maturation proteins HypC and HypD is an intermediate in the supply of cyanide to the active site iron of [NiFe]-hydrogenases. J Mol Biol 2004, 344:155-167.

7. Forzi L, Hellwig P, Thauer RK, Sawers RG: The $\mathrm{CO}$ and $\mathrm{CN}^{-}$ligands to the active site $\mathrm{Fe}$ in [NiFe]-hydrogenase of Escherichia coli have different metabolic origins. FEBS Lett 2007, 581:3317-3321.

8. Lenz O, Zebger I, Hamann J, Hildebrandt P, Friedrich B: Carbamoylphosphate serves as the source of $\mathrm{CN}^{-}$, but not of the intrinsic $\mathrm{CO}$ in the active site of the regulatory [NiFe]-hydrogenase from Ralstonia eutropha. FEBS Lett 2007, 581:3322-3326.

9. Roseboom W, Blokesch M, Bock A, Albracht SP: The biosynthetic routes for carbon monoxide and cyanide in the $\mathrm{Ni}-\mathrm{Fe}$ active site of hydrogenases are different. FEBS Lett 2005, 579:469-472.

10. Bürstel I, Hummel P, Siebert E, Wisitruangsakul N, Zebger I, Friedrich B, Lenz O: Probing the origin of the metabolic precursor of the $\mathrm{CO}$ ligand in the catalytic center of [NiFe] hydrogenase. J Biol Chem 2011, 286:44937-44944.

11. Chung KCC, Zamble DB: The Escherichia coli metal-binding chaperone SlyD interacts with the large subunit of [NiFe]-hydrogenase 3. FEBS Lett 2011, 585:291-294.

12. Rossmann R, Maier T, Lottspeich F, Böck A: Characterization of a protease from Escherichia coli involved in hydrogenase maturation. Eur J Biochem 1995, 227:545-550

13. Simpson FB, Burris $\mathrm{RH}$ : A nitrogen pressure of 50 atmospheres does not prevent evolution of hydrogen by nitrogenase. Science 1984 , 224::1095-1097.

14. Evans HJ, Russell SA, Hanus FJ, Ruiz-Argüeso T: The importance of hydrogen recycling in nitrogen fixation by legumes. In World Crops: CoO Season Food Legumes. Edited by Summerfield RJ. Boston: Kluwer Academic Publ; 1988:777-791.

15. Ruiz-Argüeso T, Imperial J, Palacios JM: Uptake hydrogenases in root nodule bacteria. In Prokaryotic Nitrogen Fixation: A Model System for Analysis of a Biological Process. Edited by Triplett EW. Wymondham, UK: Horizon Scientific Press; 2000:489-507.

16. Brito B, Martínez M, Fernández D, Rey L, Cabrera E, Palacios JM, Imperial J, Ruiz-Argüeso T: Hydrogenase genes from Rhizobium leguminosarum bv. viciae are controlled by the nitrogen fixation regulatory protein NifA. Proc Natl Acad Sci USA 1997, 94:6019-6024.

17. Hernando Y, Palacios JM, Imperial J, Ruiz-Argüeso T: The hypBFCDE operon from Rhizobium leguminosarum bv. viciae is expressed from an Fnr-type promoter that escapes mutagenesis of the fnrN gene. J Bacteriol 1995 177:5661-5669.

18. Brito B, Palacios JM, Imperial J, Ruiz-Argüeso T: Engineering the Rhizobium leguminosarum bv. viciae hydrogenase system for expression in freeliving microaerobic cells and increased symbiotic hydrogenase activity. Appl Environ Microbiol 2002, 68:2461-2467.

19. Manyani H, Rey L, Palacios JM, Imperial J, Ruiz-Argüeso T: Gene products of the hupGHIJ operon are involved in maturation of the iron-sulfur subunit of the [NiFe] hydrogenase from Rhizobium leguminosarum bv. viciae. J Bacteriol 2005, 187:7018-7026.

20. Ludwig M, Schubert T, Zebger I, Wisitruangsakul N, Saggu M, Strack A, Lenz O, Hildebrandt $\mathrm{P}$, Friedrich B: Concerted action of two novel auxiliary proteins in assembly of the active site in a membrane-bound [NiFe] hydrogenase. J Biol Chem 2009, 284:2159-2168.

21. Fu C, Maier RJ: Organization of hydrogenase gene cluster from Bradyrhizobium japonicum: sequences and analysis of five more hydrogenase related genes. Gene 1994, 145:91-96.

22. Colbeau A, Richaud P, Toussaint B, Caballero FJ, Elster C, Delphin C, Smith $R L$, Chabert J, Vignais PM: Organization of the genes necessary for hydrogenase expression in Rhodobacter capsulatus. Sequence analysis and identification of two hyp regulatory mutants. Mol Microbiol 1993, 8:15-29.

23. Maróti G, Rákhely G, Maróti J, Dorogházi E, Klement E, Medzihradsky KF, Kovács KL: Specificity and selectivity of HypC chaperonins and endopeptidases in the molecular assembly machinery of [NiFe] hydrogenases of Thiocapsa roseopersicina. Internat J Hydrogen Energy 2010, 35:3358-3370

24. Lenz O, Ludwig M, Schubert T, Burstel I, Ganskow S, Goris T, Schwarze A Friedrich $\mathrm{B}: \mathrm{H}_{2}$ conversion in the presence of $\mathrm{O}_{2}$ as performed by the membrane-bound [NiFe]-hydrogenase of Ralstonia eutropha.

Chemphyschem 2010, 11:1107-1119.

25. Watanabe S, Matsumi R, Arai T, Atomi H, Imanaka T, Miki K: Crystal structures of [NiFe] hydrogenase maturation proteins HypC, HypD, and HypE: insights into cyanation reaction by thiol redox signaling. Mol Cell 2007, 27:29-40.

26. Pettersen EF, Goddard TD, Huang CC, Couch GS, Greenblatt DM, Meng EC, Ferrin TE: UCSF Chimera-a visualization system for exploratory research and analysis. J Comput Chem 2004, 25:1605-1612.

27. Roy A, Kucukural A, Zhang Y: I-TASSER: a unified platform for automated protein structure and function prediction. Nat Protoc 2010, 5:725-738.

28. Hidalgo E, Palacios JM, Murillo J, Ruiz-Argüeso T: Nucleotide sequence and characterization of four additional genes of the hydrogenase structural operon from Rhizobium leguminosarum bv. viciae. J Bacteriol 1992, 174:4130-4139.

29. Leyva A, Palacios JM, Murillo J, Ruiz-Argüeso T: Genetic organization of the hydrogen uptake (hup) cluster from Rhizobium leguminosarum. J Bacteriol 1990, 172:1647-1655.

30. Batut J, Boistard P: Oxygen control in Rhizobium. Antonie Van Leeuwenhoek 1994, 66:129-150.

31. Stiebritz MT, Reiher M: Hydrogenases and oxygen. Chem Sci 2012, 3:1739-1751.

32. Volbeda A, Charon MH, Piras C, Hatchikian EC, Frey M, Fontecilla-Camps JC: Crystal structure of the nickel-iron hydrogenase from Desulfovibrio gigas. Nature 1995, 373:580-587.

33. Goris T, Wait AF, Saggu M, Fritsch J, Heidary N, Stein M, Zebger I, Lendzian F, Armstrong FA, Friedrich B, Lenz O: A unique iron-sulfur cluster is crucial for oxygen tolerance of a [NiFe]-hydrogenase. Nat Chem Biol 2011, 7:310-318.

34. Shomura Y, Yoon KS, Nishihara H, Higuchi Y: Structural basis for a [4Fe-3S] cluster in the oxygen-tolerant membrane-bound [NiFe]-hydrogenase. Nature 2011, 479:253-256.

35. Volbeda A, Amara P, Darnault C, Mouesca JM, Parkin A, Roessler MM Armstrong FA, Fontecilla-Camps JC: X-ray crystallographic and computational studies of the $\mathrm{O}_{2}$-tolerant [NiFe]-hydrogenase 1 from Escherichia coli. Proc Natl Acad Sci USA 2012, 109:5305-5310.

36. Imperial J, Rey L, Palacios JM, Ruiz-Argüeso T: HupK, a hydrogenaseancillary protein from Rhizobium leguminosarum, shares structural motifs with the large subunit of NiFe hydrogenases and could be a scaffolding protein for hydrogenase metal cofactor assembly. Mol Microbiol 1993, 9:1305-1306.

37. Lukey MJ, Parkin A, Roessler MM, Murphy BJ, Harmer J, Palmer T, Sargent F, Armstrong FA: How Escherichia coli is equipped to oxidize hydrogen under different redox conditions. J Biol Chem 2010, 285:3928-3938.

38. Fritsch J, Lenz O, Friedrich B: The maturation factors HoxR and HoxT contribute to oxygen tolerance of membrane-bound [NiFe] hydrogenase in Ralstonia eutropha H16. J Bacteriol 2011, 193:2487-2497.

39. Vincent JM: A manual for the practical study of root-nodule bacteria. Oxford: Blackwell Scientific Publications, Ltd.; 1970.

40. Leyva A, Palacios JM, Mozo T, Ruiz-Argüeso T: Cloning and characterization of hydrogen uptake genes from Rhizobium leguminosarum. J Bacteriol 1987, 169:4929-4934.

41. Hanahan D: Studies on transformation of Escherichia coli with plasmids. J Mol Biol 1983, 166:557-580.

42. Simon $R$, Priefer $U$, Pühler A: Vector plasmids for in-vivo and in-vitro manipulations of Gram-negative bacteria. In Molecular Genetics of the Bacteria-Plant Interactions. Edited by Pühler A. Berlin: Springer-Verlag; 1983:98-106.

43. Kovach ME, Elzer PH, Hill DS, Robertson GT, Farris MA, Roop RM, Peterson $\mathrm{KM}$ : Four new derivatives of the broad-host-range cloning vector pBBR1MCS, carrying different antibiotic-resistance cassettes. Gene 1995, 166:175-176.

44. Datsenko KA, Wanner BL: One-step inactivation of chromosomal genes in Escherichia coli K-12 using PCR products. Proc Natl Acad Sci U S A 2000, 97:6640-6645. 
45. Ruiz-Argüeso T, Hanus FJ, Evans HJ: Hydrogen production and uptake by pea nodules as affected by strains of Rhizobium leguminosarum. Arch Microbiol 1978, 116:113-118.

46. Smith PK, Krohn Rl, Hermanson GT, Mallia AK, Gartner FH, Provenzano MD, Fujimoto EK, Goeke NM, Olson BJ, Klenk DC: Measurement of protein using bicinchoninic acid. Anal Biochem 1985, 150:76-85.

47. Sambrook J, Russell DW: Molecular Cloning: A Laboratory Manual. 3rd edition. N.Y.: Cold Spring Harbor; 2001

48. Brito B, Palacios JM, Hidalgo E, Imperial J, Ruiz-Argüeso T: Nickel availability to pea (Pisum sativum L.) plants limits hydrogenase activity of Rhizobium leguminosarum bv. viciae bacteroids by affecting the processing of the hydrogenase structural subunits. J Bacterio/ 1994, 176:5297-5303.

doi:10.1186/1471-2180-12-256

Cite this article as: Albareda et al.: Dual role of HupF in the biosynthesis of [NiFe] hydrogenase in Rhizobium leguminosarum. BMC Microbiology 2012 12:256.

\section{Submit your next manuscript to BioMed Central and take full advantage of:}

- Convenient online submission

- Thorough peer review

- No space constraints or color figure charges

- Immediate publication on acceptance

- Inclusion in PubMed, CAS, Scopus and Google Scholar

- Research which is freely available for redistribution 